\title{
Cidade seu nome é palavra
}

FABIOOLA TASCA

\section{Resumo}

O texto evoca a potência latente das relações entre arte e cidade, procurando sublinhar a dimensão de inventividade instaurada pela palavra, cujo manejo é considerado aqui como uma questão constitutiva da porosidade desejável entre vida ordinária e imprevisibilidade. Pretende-se apontar para a questão da cidade enquanto espaço onde a experiência pode ter lugar.

Palavras-chave: Intervenção urbana, cidade, experiência 


\title{
City its name is word
}

\author{
FABIOOLA TASCA
}

\begin{abstract}
This texts evocates the latent inner strength of the relation between Art and City. Its goal is to underline the dimension of inventiveness instituted by the power of words, power considered here as a main constituent of the relation between ordinary life and the unforeseeable. It is intended to point to the issue of the city as space where the experience can take place.
\end{abstract}




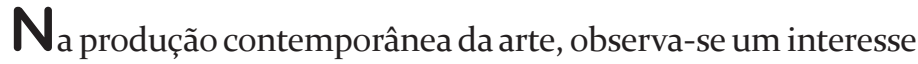
crescente por intervir e agir em contextos urbanos. A presença da arte no cenário da cidade expressa um desejo de interromper o curso normal da vida cotidiana e, assim, iluminar algumas de suas dimensões. Subjacente a esse desejo, há a crença de que a arte tem a capacidade ou o poder de nos permitir compreender a vida de maneira mais complexa e interessante.

Tal crença, aqui, será subsidiada pela "convicção de que as palavras produzem sentido, criam realidades e, às vezes, funcionam como potentes mecanismos de subjetivação" (BONDÍA, 2002, p. 21). Neste sentido, este texto pretende sugerir que avizinhar as palavras "cidade" e "arte" consiste não só em uma ambição, mas, em uma estratégia de instauração de outras realidades.

Promover o estranhamento do familiar, despertar os sujeitos de uma suposta anestesia, evocar a multiplicidade de sentidos que as cenas mais prosaicas podem suscitar, convidar o citadino a estabelecer uma relação mais entusiasmada e consequente com o que o cerca são todas ambições e formulações que habitam os discursos que investem na promoção de relações entre arte e cidade. Tais perspectivas tendem a compreender a arte enquanto uma maneira singular de estabelecer relações com contextos diversos, de afetar e ser afetada. Um modo específico de experiência é entendido aqui nos termos propostos por Jorge Larrosa Bondía (2002) como aquilo que nos acontece, o que se passa conosco e nos toca. Tal compreensão do termo "experiência" solicita uma relação dilatada com o tempo, uma atitude de disponibilidade e abertura, para a qual a conexão entre os termos "arte" e "cidade" nos interpela:

$\mathrm{O}$ que pode a arte na cidade?

Intervenções como as do Grupo Poro', formado por Marcelo Terça Nada! e Brígida Campbel, afirmam que a arte pode despontar no sono corriqueiro e nos convidar a habitar a cidade de maneiras insuspeitas. Em fevereiro de 2009, o Poro espalhou 
faixas pelos Bairros Santa Tereza, Horto e Floresta, em Belo Horizonte. As costumeiras tiras de tecidos que anunciam promoções, vendem apartamentos, oferecem recompensas pelo resgate de cães perdidos ou felicitam vestibulandos convidavam os transeuntes a se relacionarem com a cidade a partir de uma perspectiva menos instrumental: Perca Tempo, Veja através, Assista à sua máquina de lavar como se fosse um vídeo.

A arte pode nos convidar a perceber outras cidades na cidade. Numa perspectiva que lança mão da sutileza como estratégia de ação, situam-se as delicadas e imprevisíveis intervenções do artista paulista Rubens Mano. Intervenções - como um bueiro iluminado no Bairro Bom Retiro, em São Paulo - que desafiam nossos viciados códigos perceptivos, conduzindo o olhar para uma região costumeiramente negligenciada do espaço urbano. De uma maneira geral, só vemos determinadas áreas da cidade e equipamentos urbanos quando estes não funcionam. A apreensão da estrutura urbana enquanto uma diagramação complexa que possibilita o curso ordinário da vida cotidiana permanece, num certo sentido, fora do alcance perceptivo imediato. Que tipo de experiência pode configurar esse encontro com um bueiro iluminado? Estranhamento, encantamento, indiferença?

Ao contrário de Rubens Mano, estratégias de ação como as de Christo e Jean Claude, de empacotamento de um edifício público da importância do Reichstag (o parlamento alemão), em Berlim, lançam mão de expedientes espetaculares que mobilizam inúmeras pessoas e alcançam uma repercussão midiática. As intervenções de Christo e Jean Claude nos dizem que a arte na cidade pode constituir-se em um grande evento, reunindo os esforços de mais de 20 anos de persistência e produzindo imagens de extremo impacto.

Também o artista Santiago Sierra produziu inúmeros trabalhos em contextos urbanos, conforme assinala a curadora mexicana Taiyana Pimentel:

No começo de sua obra havia um forte interesse por um manejo da rua e do que ocorria na rua, acho que com o tempo ele foi deslocando esse problema da rua em direção à instituição, foi levando as prostitutas aos museus, os desempregados, os desalojados até o museu e foi gerando aí um problema de outra ordem política, mas no princípio Santiago se deslocava à rua para trabalhar (PIMENTEL in TASCA, 2012, p. 251).

Um dos trabalhos mais emblemáticos desse momento é Obstrucción de una vía con un contenedor de carga, realizado 
no Anillo Periférico Sur, na Cidade do México, em 1998. O trabalho consistiu na ação - realizada por um motorista - de manobrar um caminhão de carga da empresa de sucos Jumex ${ }^{2}$, de maneira a posicionar a carroceria em sentido perpendicular ao trânsito e, por 5 minutos, produzir uma congestão do tráfego. A ação gerou um vídeo e sequências fotográficas. Caminhando na contramão de perspectivas que supõem que a arte possa melhorar a vida nas cidades, Sierra produz um trabalho que causa distúrbio, que dificulta o fluxo normal da megalópole, insinuando que arte na cidade pode ser incômoda e hostil; propondo que a arte pode não ser conveniente à vida urbana.

A direção para a qual o trabalho de Sierra aponta parece corroborar o aspecto não instrumental de relação com a cidade que encontramos nas faixas do Poro, no bueiro iluminado de Mano, ou mesmo na ocultação/revelação do Reichstag. Mas o trabalho de Sierra, ao investir no incômodo e na aspereza - qualidades distantes das estratégias dos outros artistas - confronta as relações de eficiência que, de maneira geral, regem os deslocamentos e atitudes em relação à cidade. Em nenhum dos procedimentos mencionados há um investimento tão deliberado em produzir a perturbação como no caso de Sierra e a perturbação é entendida aqui como um dos modos possíveis de aparição da experiência. Não se trata de advogar que sigamos a direção apontada por Obstrucción..., que perturbemos deliberadamente a dinâmica urbana, já tão agredida por inúmeros agentes e instâncias; mas pareceme especialmente valioso para alcançarmos uma compreensão da arte como modo específico de experiência, que ela se apresente enquanto certa subtração do caráter utilitário, pragmático e eficiente que orienta a vida ordinária. Que essa subtração possa sempre ser instrumentalizada para diversos fins, talvez fosse um caminho possível para a discussão, mas não vamos persegui-lo aqui. Nesse sentido, a subtração do caráter instrumental tornase mais evidente quando se mostra como avesso daquilo que se supõe desejável: a arte como a realização de anseios e expectativas de uma ordem social, política, econômica etc.

Projetos como o Arte/Cidade 3 , em São Paulo, coordenado por Nelson Brissac Peixoto, ou inSITE4, na fronteira Tijuana/San Diego, apostam no poder da arte em produzir um olhar crítico sobre a realidade contemporânea, investindo nos artistas como interventores especializados em provocar tanto o encantamento, como o debate. Grande parte dos trabalhos de arte urbana situa-se no contexto de projetos como esses que constituem as condições institucionais para práticas que envolvem desafios e demandas muito distintas daquelas relacionadas aos trabalhos produzidos 
para o contexto de galerias e museus. Assim, o aparato institucional desses projetos provêa mediação necessária para tais práticas.

Os exemplos de arte no contexto das cidades são inúmeros e, embora cada trabalho elabore suas especificidades, constituindo uma singularidade, muitos lançam luz, com maior ou menor propriedade, sobre os conceitos de espaço público, esfera pública, comunidade, participação política e correlatos. Entretanto - é sempre bom lembrar - os trabalhos não constituem ilustrações de tais conceitos, antes, estabelecem com eles um jogo de iluminação recíproca: iluminam os conceitos e são por eles iluminados.

Tal campo conceitual participa das reflexões situacionistas sobre o espaço urbano, local que compreendem como sendo o foco da ação artística. O grupo de artistas, pensadores e ativistas que compunha a Internacional Situacionista ${ }^{5}$ lutava contra certa passividade do homem moderno e afirmava que num futuro todos seriam artistas, todos seriam situacionistas.

A mensagem central dos Situacionistas é que o homem atual não é um ator, mas um mero espectador. Em seu papel passivo aceita o sistema social e, na prática, reproduz a cultura que o sufoca e que se caracteriza pelo trabalho rotineiro, o desperdício do tempo livre, a manipulação dos meios, a arte excludente e burocrática, a cultura estereotipada, os ritos empobrecedores, o conformismo e o tédio. Em contraste, os valores Situacionistas são a interação social, o diálogo e a renovação do comportamento. Para eles, é requerida uma reversão ética que permita equidade na participação e recreação lúdica, mais do que equidade na distribuição do ingresso ou consumo de bens, que consideram bens empobrecidos ${ }^{6}$ (tradução minha).

A maneira como avaliam o automóvel - bem fundamental para a sociedade moderna - é bastante elucidativa do que entendem como "bens empobrecidos". Eles criticam certa visão urbanística que privilegia em seus projetos o automóvel individual (e a motocicleta) como meios de transporte. O automóvel, nessa perspectiva, "é [compreendido como] a principal materialização de um conceito de felicidade que o capitalismo desenvolvido tende a divulgar para toda a sociedade. O automóvel como supremo bem de uma vida alienada" (JACQUES, 2003, p. 112).

Para os situacionistas, a arte deveria ser "superada" e o meio urbano seria o local onde tal superação se daria. Superar a arte é concebê-la não mais como uma atividade especializada e separada da práxis vital, mas transformá-la no que seria a construção da vida cotidiana, uma ambição vanguardista. 
Este conceito de 'situação', que nomeia o grupo, vai buscar suas bases na "teoria dos momentos", descrita por [Henri] Lefebvre, e apoiar-se em uma intenção de incorporar a vida cotidiana às reflexões sobre arte, lazer e vida urbana. A ideia de construir situações propõe que a vida cotidiana poderia incitar paixões que provocam um sentido de jogo no espaço urbano, onde, apesar da repetição de hábitos, abre-se sempre um espaço para o aleatório, incontrolável, o apaixonante. (...) A situação seria construída, então, como um momento determinado por uma duração prevista e que deveria acontecer em um lugar específico (DIAS, 2007, p. 38).

Os situacionistas propõem uma construção coletiva das cidades; não se trata da projeção de cidades ideais, mas, de uma intervenção no meio urbano, no sentido de lançar mão da arquitetura e do urbanismo como ferramentas na construção de ambiências que permitam aos sujeitos uma relação participativa com o cotidiano.

A crítica e a construção situacionistas referem-se, em todos os níveis, ao valor de uso da vida. Como nossa noção de urbanismo é uma crítica ao urbanismo; como nossa experiência dos lazeres é de fato uma recusa do lazer (no sentido dominante de separação e passividade); do mesmo modo, se designamos nosso campo de ação na vida cotidiana, trata-se de uma crítica da vida cotidiana... (JACQUES, 2003, p. 129).

Nomeado como Urbanismo Unitário, as ideias situacionistas a respeito da cidade propunham formas efêmeras de vivenciá-la, como a psicogeografia e a deriva. A primeira é compreendida como um método, uma maneira de avaliar a influência do meio geográfico sobre o comportamento afetivo dos indivíduos, já a segunda é uma prática de apreensão do espaço urbano, uma técnica de andar sem rumo.

Qual seria a importância atual do pensamento situacionista sobre a cidade? Paola Berenstein Jacques afirma que tal pensamento poderia funcionar como antídoto à espetacularização das cidades contemporâneas.

Os situacionistas chegaram a uma convicção exatamente contrária à dos arquitetos modernos. Enquanto os modernos acreditaram, num determinado momento, que a arquitetura e o urbanismo poderiam mudar a sociedade, os situacionistas estavam convictos de que a própria sociedade deveria mudar a arquitetura e o urbanismo (JACQUES, 2003, p. 19). 
"O situacionista considera o ambiente e a si próprio como plásticos" (JACQUES, 2003, p.19) e, a partir dessa premissa, acredita que por meio da construção de situações pode-se alcançar a transformação revolucionária da vida cotidiana. As concepções situacionistas são muito vigorosas e ambiciosas, mas não é preciso investir em muitos argumentos para afirmarmos que suas propostas não alcançaram efetividade. $\mathrm{O}$ cotidiano da maioria das pessoas está longe de ser apaixonante, as ideias de jogo, lazer, participação, a cidade como lugar de encontro, enfim, as premissas que regem as propostas situacionistas parecem muito distantes do nosso mundo contemporâneo. A transformação revolucionária da vida cotidiana não se cumpriu. Pelo menos não no sentido emancipatório subjacente às suas propostas. A arte não foi superada.

Eis aqui a palavra "fracasso"?

Num certo sentido poderíamos entender essa palavra como algo que nos concerne enquanto habitantes do século XXI. Pensar a arte em relação à contemporaneidade talvez consista, em alguma medida, no exercício de deslindar relações entre arte e fracasso. $\mathrm{O}$ texto poderia agora recorrer ao argumento do fim, o fim da história, o fim das grandes narrativas, o fim das utopias, o fim da própria arte. Fim como fracasso? Fim pode ser uma boa palavra na medida em que oferece as condições de possibilidade para a inauguração de novos começos.

Um novo começo, aqui, poderia recolocar a pergunta inicial. Não mais indagar sobre a potência da arte em relação à cidade (o que pode a arte na cidade?), mas, de preferência, articular a vizinhança entre arte e cidade considerando a "palavra" como uma questão.

No artigo "Não mais, não ainda: a palavra na democracia e na psicanálise", Jurandir Freire Costa oferece algumas pistas que este texto ambiciona perseguir. Costa mobiliza autores e conceitos para sublinhar a função iniciadora e mediadora da palavra. A palavra é prenhe de futuro porque inaugura realidades possíveis. $\mathrm{O}$ argumento, embora pareça hermético, carrega uma simplicidade desconcertante:

Por exemplo, o uso da palavra 'pedra' pode ser ensinado a uma criança como sendo o termo que se refere a alguma coisa que preexiste à sua nomeação. Mas no momento em que a pedra torna-se 'pedra' deixa de ser o inerte indeterminado para ser a 'pedra' do jardineiro; do decorador; do pedreiro; da criança brincando; dos revoltosos em luta contra o poder; da maioria 
que apedreja o condenado; do poeta que pensa no sentido da vida; do religioso que pede compaixão pelo outro; do pintor; do geólogo; do paleontologista; do físico ou do químico. Portanto, a entidade 'pedra' não teve sua essência revelada quando foi dita. A palavra 'pedra' não descobre a 'pedridade da pedra' que estava lá, escondida por nossa ignorância e lutando para continuar oculta ou vir à luz do conhecimento. A nomeação pode designar o que existe ou criar o inexistente no ato de dizê-lo. [...] Toda realidade conhecida é realidade sob descrição. Redescrever, por conseguinte, é sempre inaugurar, ou seja, contrastar o que é dito com o que se conhece, para mostrar o caráter inédito daquilo que é falado de uma nova maneira (COSTA, 1998, p. 110).

Costa prossegue, assinalando que a psicanálise, assim como a democracia, faz parte de uma forma de vida na qual o sujeito é pensado como um futuro imprevisível e "a imprevisibilidade, apesar de inquietante, deve ser investida como desejável" (COSTA, 1998, p. 109). Sim, há algo de inquietante na imprevisibilidade, tal como Costa nos esclarece na continuidade dos argumentos que maneja. Há algo de inconveniente na imprevisibilidade, poderíamos acrescentar. O que não está previsto é, via de regra, inadequado ao funcionamento da vida ordinária. Inadequado no sentido de não perfeitamente ajustado a um objetivo. A imprevisibilidade tende, então, a fazer um apelo que não convém ao funcionamento apropriado da dinâmica urbana, orientada por demandas e urgências. Obstrucción de una via con un contenedor de carga torna o argumento facilmente compreensível. A congestão do tráfego, ocasionada pela manobra imprevista do caminhão, produz distúrbio, disfunção na via urbana. O imprevisível aqui é justamente o elemento que perturba a ordem, ordem que mantém as coisas em seus alojamentos, as pessoas em determinados lugares, as engrenagens em funcionamento.

A arte, desde que assume como sua tarefa certo programa de ruptura com a tradição, vem esposando a ambição de desestabilizar a ordem, de tirar as coisas dos seus lugares habituais, de instaurar fissuras no tecido aparentemente liso da realidade. São essas as manobras ambiciosas do ideário modernista as que procurei sugerir que tenham algo a ver com o termo "fracasso". Mas cabe lembrar também que este texto vinha conduzindo a compreensão de um suposto fracasso, no sentido de envolvê-la com o ato de assumi-lo, o que traria, então, um sentido de novo começo. Não como tabula rasa, mas como palavra fundadora, implicando aí suas funções iniciadora e mediadora a um só tempo. 
Se a produção artística contemporânea apresenta algum caráter de positividade, para além de ser definida como aquilo que não é mais, talvez tal caráter possa estar relacionado a um reclame pela "palavra fundadora do sujeito" que se inscreve entre o "não mais" e o "não ainda".

O quê de inventivo comporta a cidade? Tem a arte alguma participação na possibilidade de a cidade se constituir como lugar da experiência?

A advertência de Nelson Brissac Peixoto nos é útil aqui: a arte enquanto intervenção no contexto urbano não se confunde com administração do espaço urbano. Para Peixoto, o espaço urbano é justamente o resultado da intervenção artística e não o campo pré-organizado para que a intervenção se dê, o que seria algo como um continente para o trabalho. "O que está em discussão é o espaço urbano, não o que já está garantido" (PEIXOTO, 1998, p. 117).

O trabalho de arte no contexto da cidade redefine o espaço no qual tem lugar, assim como a palavra fundadora do sujeito inaugura uma realidade. O exercício de conexão entre cidade e palavra, tal como ensaiado no título deste texto, pretende colocar em foco uma noção especialmente significativa para o debate sobre a potência das relações entre arte e cidade, a qual orienta as ambições de certas práticas artísticas urbanas: propor os locais de passagem das grandes cidades como locais de experiência.

Interessada em tomar parte nessa discussão, nos dias 27 e 29 de Junho de 2010 realizei a ação Primeira Pessoa na Barragem Santa Lúcia, em Belo Horizonte. O trabalho foi financiado pelo Fundo de Projetos Culturais do Município e contou com a participação de três funcionários da prefeitura. A ação consistiu no gesto de distribuir 41 boias na lagoa da barragem, utilizando um pequeno barco. As boias eram câmaras de ar de pneus de caminhão sobre as quais estavam pintados todos os pronomes pessoais relativos às pessoas do discurso, exceto aqueles relacionados à primeira pessoa do singular e do plural. A ação procurava manter-se num ritmo lento, no qual as boias eram distribuídas com vagar. Cada uma delas era disposta em um determinado ponto da lagoa e dali conduzida pela ação do vento em direção à margem, na qual ia se formando um aglomerado de boias e pronomes. A ação durou aproximadamente três horas e gerou um vídeo produzido por Daniel Carneiro, disponível em: http://vimeo.com/19717261 e fotografias produzidas por Pedro Davi. 

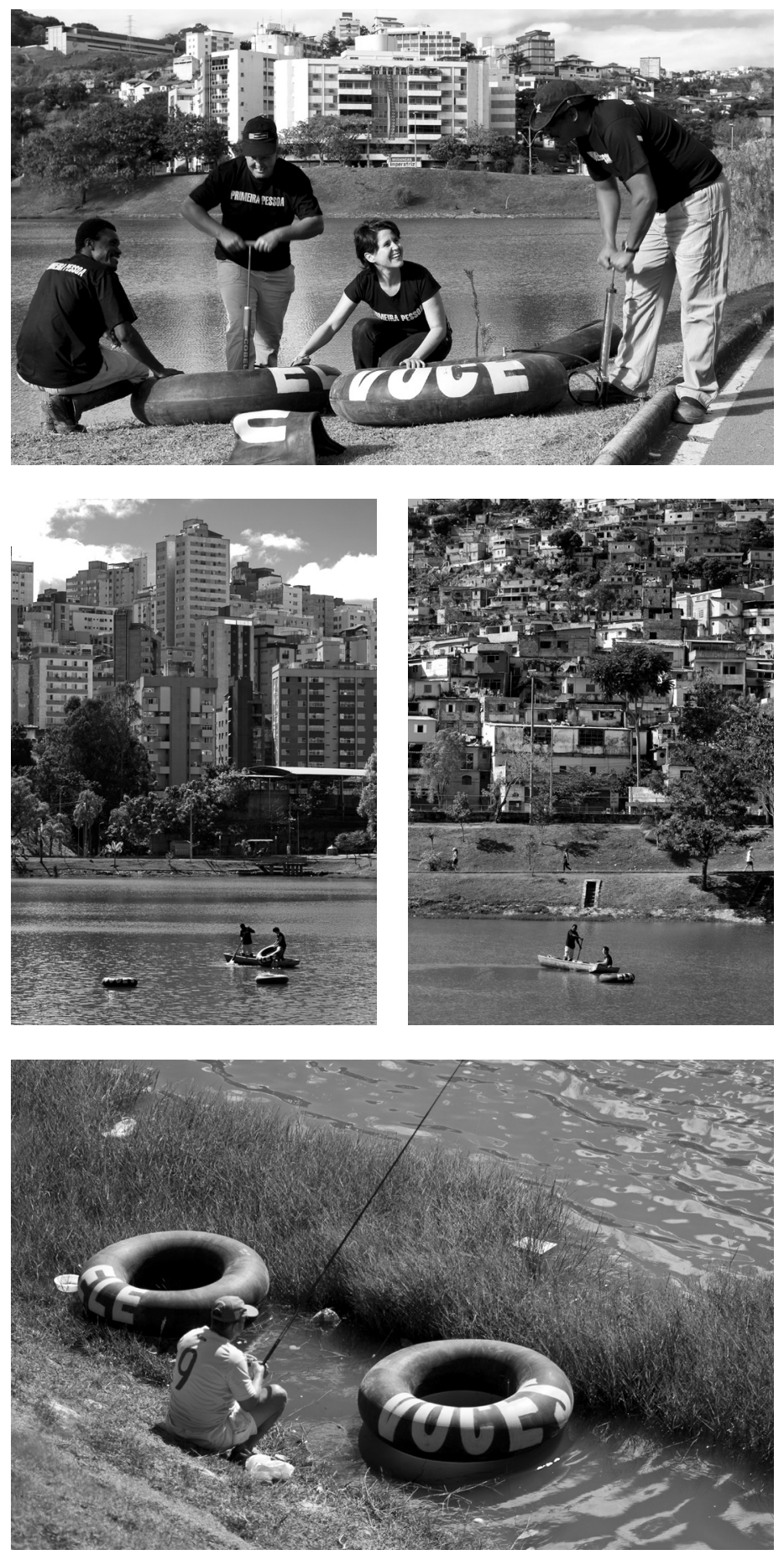

Figura 1

Primeira Pessoa.

Fotografia Pedro David

Figuras 2 e 3

Primeira Pessoa.

Fotografia Pedro David

Figura 4

Primeira Pessoa.

Fotografia Pedro David 


\section{Referências}

BONDÍA, Jorge Larrosa. Notas sobre a experiência e o saber de experiência. Tradução João Wanderley Geraldi. Revista Brasileira de Educação, Rio de Janeiro, n. 19, jan/fev/mar/abr 2002.

COSTA, Jurandir Freire. Não mais, não ainda: a palavra na democracia e na psicanálise. Revista USP, São Paulo, mar./ mai., p. 108-119, 1998.

DIAS, Juliana Michaello M. O grande jogo do porvir: a Internacional Situacionista ea idéia de jogo urbano. Estudos e pesquisas em psicologia, UERJ, Rio de Janeiro, ano 7, n. 2, 2 $2^{\underline{a}}$ Semestre de 2007. p. 37 a 49. Disponível em: <http://pepsic.bvs psi. org.br/pdf/epp/v7n2/v7nzao6.pdf $>$. Acesso em: 23 fev. 2011.

GONZÁLEZ-ARÉCHIGA, Bernardo. Creando Situaciones sin retorno: Algún día todos seremos artistas, todos seremos Situacionistas. p.1. Disponível em: <http://www.itesm.mx/egap/ que_es_egap/situacionista.pdf $>$. Acesso em: 13 jun. 2013.

JACQUES, Paola Berenstein (Org.). Apologia da deriva: escritos situacionistas sobre a cidade. Tradução de Estela dos Santos Abreu. Rio de Janeiro: Casa da Palavra, 2003. 158 p.

LINDEMANN, Adam. Coleccionar Arte Contemporáneo. Köln: Taschen, 2006. 298p.

OLIVEIRA, Luiz Sérgio de. InSITE: práticas de arte pública na fronteira entre dois mundos. 2006. Tese (Doutorado em Artes Visuais) - Escola de Belas Artes, Universidade Federal do Rio de Janeiro, Rio de Janeiro. 472 p. 2006.

PEIXOTO, Nelson Brissac. Arte \& Cidade. In: Arte Pública. Trabalhos apresentados nos Seminários de Arte Pública realizados pelo SESC e pelo USIS, de 17 a 19 de outubro de 1995 e 21 de novembro de 1996. São Paulo: SESC, 1998. p. 113-120.

SITUACIONISTA: Teoria e prática da revolução. Tradução de Francis Wuillaume e Leo Vinicius. São Paulo: Conrad Editora do Brasil, 2002. 153 p. Título original: Internationale Situationniste.

TASCA, Fabíola Silva. Por um conceito do político na arte contemporânea: o Fator Santiago Sierra. 2011. 311 p. Tese (Doutorado em Artes) Escola de Belas Artes, Universidade Federal de Minas Gerais, Belo Horizonte, 2011.

\section{NOTAS}

1. Optei por não apresentar as imagens dos trabalhos artísticos mencionados, uma vez que não possuo o direito de uso de tais imagens, as quais estão acessíveis na internet. 
2. Eugênio Lopez, único herdeiro da empresa de sucos Jumex, é o mecenas mais importante de arte contemporânea do México e um dos maiores colecionadores das obras de Santiago Sierra.

3. A primeira edição do Arte/Cidade: Cidade sem janelas foi realizada em 1994 e ocupou o antigo Matadouro Municipal da Vila Mariana, em São Paulo. A cidade e seus fluxos também foi realizado em 1994 e ocupou o topo de três edifícios na região central de São Paulo. Em A cidade e suas histórias, realizado em 1997, focalizou-se uma estação de trens (Estação da Luz) e um trecho ferroviário que atravessa os locais significativos do período fabril da cidade de São Paulo. "Arte/Cidade - Zona Leste" ocorreu em 2002, numa área de cerca de 10 km2, na região leste de São Paulo.

4. O inSITE consiste num projeto de colaboração binacional entre México e Estados Unidos e comissiona artistas para trabalharem na região fronteiriça de Tijuana/San Diego. "Um projeto que, desde seus primórdios, vem ecoando a própria história da arte pública na contemporaneidade, expandindo-se a partir dos projetos de arte-instalação (1992 e 1994), para se embrenhar pelas especificidades naturais, físicas e políticas da região, em lugares nunca antes explorados (1994 e 1997), em uma aproximação cautelosa e gradativa com o contexto e com as comunidades (1997 e 2000), até esmerar-se em um processo de plena colaboração com as comunidades, nos chamados community-based projects de 2005 " (Oliveira, 2006, p.3).

5. "A Internacional Situacionista foi criada em julho de 1957, em Cosio d'Arroscia, na Itália, a partir da fusão de três grupos: A Internacional Letrista (de onde vieram Debord e Michèle Bernstein), o Movimento Internacional por uma Bauhaus Imaginista (de onde vinham, entre outros, os artistas Pinot-Gallizio e Asger Jorn, este integrante também do grupo COBRA) e a Associação Psicogeográfica de Londres (que foi criada no próprio encontro em Cosio d'Arroscia e se resumia a um só integrante, Ralph Rumney). Era um grupo pequeno no início e sempre ficou assim. Teve, ao longo de seus 12 anos de existência, um total de 70 integrantes (63 homens e 7 mulheres), de 16 nacionalidades diferentes. Mas devido às constantes exclusões ( 45 dos 70 foram excluídos), a IS poucas vezes teve mais de 10 integrantes ao mesmo tempo" (SITUACIONISTA, 2002, p.14-15).

6. "El mensaje central de los Situacionistas es que el hombre actual no es un actor sino um mero espectador. En su rol pasivo acepta el sistema social y, en la práctica, reproduce la cultura que lo agobia y se caracteriza por el trabajo rutinario, el desperdicio del tiempo libre, la manipulación de los medios, el arte excluyente y burocrático, la cultura estereotipada, los ritos empobrecedores, el conformismo y el aburrimiento. En contraste, los valores de los Situacionistas son la interacción social, el diálogo y la renovación del comportamiento. Para ellos, se requiere una reversión ética que permita equidad en la participación y la recreación lúdica más que la equidad en la distribución del ingreso o consumo de bienes, que consideran bienes empobrecidos" (GONZÁLEZ-ARÉCHIGA, s/d, p.1).

Recebido em: 12/03/14

Aceito em: 11/07/14

\section{FABÍOLA TASCA}

fabiolaabh@gmail.com

Artista plástica e pesquisadora. Doutora em Artes pela EBA/UFMG. Desde 2005 é professora na Escola Guignard /UEMG, onde vem desenvolvendo uma pesquisa que discute relações entre arte e trabalho na contemporaneidade: em obra project [2012/2016]. 